\title{
Desenvolvimento rural: a importância das TICS e dos controles econômicos e financeiros na visão dos agricultores familiares do Vale do Caí-RS
}

Fernando Batista Bandeira da Fontoura

fontoura.custos@ibest.com.br Cruz do Sul, Rio Grande do Sul, Brasil

\section{Cidônea Machado Deponti} cidonea@unisc.br

Universidade de Santa Cruz do Sul, Santa Cruz do Sul, Rio Grande do Sul, Brasil

\begin{abstract}
RESUMO
Este ensaio tem como objetivo principal entender a importância das TICs (Tecnologias da Informação e Comunicação) e dos controles econômicos e financeiros na visão dos agricultores familiares do Vale do Caí- RS, bem como as mudanças socioeconômicas ocorridas principalmente após 1970 e seus reflexos para o meio rural. Foi realizado um levantamento empírico junto ao Projeto "O uso e a apropriação das TICs pela agricultura familiar no Vale do Caí-RS" para 10 famílias de agricultores familiares visando entender a percepção desses agricultores sobre a temática. $O$ estudo apresenta a discussão sobre desenvolvimento rural e sobre a importância das TICs. Também apresenta os procedimentos metodológicos, bem como, sugestões iniciais de controles econômicos e financeiros aplicados à gestão rural. Concluiu-se que apesar de não se pretender generalizar pode-se afirmar preliminarmente que os agricultores têm influência típica dos sistemas capitalistas monoprodutores e carência de orientação sobre a utilização das ferramentas citadas para melhoria na gestão da propriedade rural, entendendo, ainda que a dimensão econômica e financeira é apenas uma entre várias questões socioambientais importantes para o desenvolvimento rural.
\end{abstract}

PALAVRAS-CHAVE: TICS, desenvolvimento e gestão rural. 


\section{INTRODUÇÃO}

Um assunto a ser discutido nas ciências sociais aplicadas é o papel dos agricultores familiares no desenvolvimento regional. Este ensaio objetiva analisar a percepção da importância da TICs (Tecnologias da Informação e Comunicação) na visão dos agricultores como um fator importante para o desenvolvimento rural.

O desenvolvimento rural é um fator relevante para o desenvolvimento regional na perspectiva que considera as múltiplas possibilidades e as diferentes dimensões e escalas e não na visão predominante, industrializadora com viés meramente economicista unidimensional (MARCUSE, 1973). O desenvolvimento regional depende de uma série de complexos elementos e de especificidades, vinculados a questões territoriais, culturais, políticas, econômicas, sendo que e o desenvolvimento e a gestão rural são elementos importantes neste contexto. (BARQUERO 2001; DALLABRIDA 2010; BERNSTEIN 2011; BENKO 1999).

Esta visão está alinhada a perspectiva ancorada por autores como Harvey (1992), Toffler (1995) e Ramos (1989) que fazem uma crítica sobre a crise do Taylorismo-fordismo como modelo econômico, de organização da produção e de entendimento social.

Este alerta é muito relevante, pois se este modelo já está em crise para organizações, muito mais para o desenvolvimento rural com todas as suas especificidades regionais. Faz-se mister pesquisas envolvendo a questão e buscando entender a genealogia destes processos, com viés epistemológico voltado para a percepção social, para estudos analítico-interpretativos de natureza emancipadora e não para modelos generalizadores, massificados, lineares baseados na sociedade industrial ou de mercado, meramente baseados na acumulação rígida de capital. (BOLTANSKI E CHIAPELLO, 2009; PAULA, 2010).

Este artigo tem como objetivo principal fazer uma leitura inicial do desenvolvimento rural sob a ótica do desenvolvimento regional e da importância das TICs, bem como da utilização de controles econômicos e financeiros para a gestão rural. $O$ estudo irá se basear na percepção dos agricultores familiares do Vale do Caí sobre a importância destas ferramentas para gestão rural.

Cabe ressaltar que a compreensão de desenvolvimento regional refere-se muito além do conceito de crescimento econômico, como muito tempo foi difundido por autores em especial da escola clássica de economia. Neste sentido, este ensaio objetiva analisar a percepção dos agricultores familiares e apresentar controles básicos para melhoria da gestão rural, superando a utilização de conceitos apenas econômicos e financeiros.

Parte-se de informações para melhoria da compreensão e do entendimento dos agricultores sobre suas atividades e sobre a gestão da propriedade rural, sem com isso pregar de forma ingênua que basta fazer controles para que se tenha desenvolvimento rural.

Como procedimentos metodológicos optou-se pela pesquisa qualitativa em profundidade com o levantamento dos dados através de um piloto com 10 agricultores familiares localizados no Vale do Caí-RS, principalmente do interior de Montenegro-RS, nas localidades de Costa da Serra e Campo do Meio (Lajeadinho, Santos Reis e Vapor Velho), integrantes do projeto de pesquisa acima referido, vinculado ao Programa de Pós-Graduação em Desenvolvimento Regional da Universidade de Santa Cruz do Sul- RS.

A compreensão de desenvolvimento rural neste ensaio é tida como um processo social imbricado em questões culturais voltado para uma visão 
emancipadora do agricultor familiar no entendimento e nas ações no meio rural. (RAMOS 1989; FREIRE 2005). Portanto, o simples desenvolvimento de controles econômicos e financeiros ou a utilização de tecnologias não garante o tão desejado desenvolvimento rural.

O presente artigo divide-se em três seções, além desta introdução e das considerações finais. Na primeira seção, realiza-se uma revisão bibliográfica sobre TICs, gestão rural e a importância dos sistemas de controles. Na segunda seção apresenta-se os procedimentos metodológicos e na terceira seção a análise dos resultados.

\section{CRESCIMENTO, DESENVOLVIMENTO E DESENVOLVIMENTO RURAL}

O referencial teórico deste ensaio faz uma análise crítica da visão hegemônica de crescimento baseada na acumulação de capital e na produção em massa que foi implementada em alguns aspectos, também na área rural. Parte-se da leitura de Schumpeter (1982), visando fazer uma discussão sobre a dicotomia crescimento e desenvolvimento, bem como o desenvolvimento rural.

A leitura de Schumpeter vem a romper com o paradigma predominante dos autores considerados clássicos na economia, principalmente no que se refere à visão de desenvolvimento e não puramente de crescimento econômico. Neste sentido, podem-se considerar os agricultores familiares ${ }^{1}$ como pequenas organizações inseridos no contexto territorial com particularidades e especificidades que podem ser alinhadas ao desenvolvimento regional. (BARQUEIRO, 1999; BENKO, 1999). ${ }^{2}$

Dupas (2007) adverte que em pleno século XXI um grande paradoxo continua instalado. Neste paradigma a capacidade de produzir mais e melhor não cessa de crescer assumida pelo discurso hegemônico do progresso trazido pela globalização, questionando: Somos por conta desse tipo de "desenvolvimento" mais sensatos e mais felizes?

O capitalismo regulado pela intervenção do estado havia bloqueado durante várias décadas do século XX o conflito entre as classes,

\footnotetext{
${ }^{1} \mathrm{Na}$ Lei $\mathrm{n}^{\mathrm{0}} 11.326 / 96$ a agricultura familiar foi assim definida:

Art. $3^{\circ}$ Para os efeitos desta Lei considera-se agricultor familiar e empreendedor familiar rural aquele que pratica atividades no meio rural, atendendo, simultaneamente, aos seguintes requisitos: I - não detenha, a qualquer título, área maior do que 4 (quatro) módulos fiscais; II - utilize predominantemente mão de obra da própria família nas atividades econômicas do seu estabelecimento ou empreendimento; III - tenha renda familiar predominantemente originada de atividades econômicas vinculadas ao próprio estabelecimento ou empreendimento; IV - dirija seu estabelecimento ou empreendimento com sua família. $\S 1^{\circ} \mathrm{O}$ disposto no inciso I do caput deste artigo não se aplica quando se tratar de condomínio rural ou outras formas coletivas de propriedade, desde que a fração ideal por proprietário não ultrapasse 4 (quatro) módulos fiscais. § $2^{\circ}$ São também beneficiários desta Lei: I - silvicultores que atendam simultaneamente a todos os requisitos de que trata o caput deste artigo, cultivem florestas nativas ou exóticas e que promovam o manejo sustentável daqueles ambientes; II - aquicultores que atendam simultaneamente a todos os requisitos de que trata o caput deste artigo e explorem reservatórios hídricos com superfície total de até 2 ha (dois hectares) ou ocupem até $500 \mathrm{~m}^{3}$ (quinhentos metros cúbicos) de água, quando a exploração se efetivar em tanques-rede; III - extrativistas que atendam simultaneamente aos requisitos previstos nos incisos II, III e IV do caput deste artigo e exerçam essa atividade artesanalmente no meio rural, excluídos os garimpeiros e faiscadores; IV pescadores que atendam simultaneamente aos requisitos previstos nos incisos I, II, III e IV do caput deste artigo e exerçam a patinkidgde pesqueira artesanalmente. (GOMES, 2014, p. 33-34).

${ }^{2}$ Com isso não se quer considerar os agricultores familiares meros produtores de mercadorias, mas sim agentes envolvidos em arranjos regionais territorializados.
} 
durante esse período, apenas nas periferias do sistema capitalista estas tensões prevaleciam. Na verdade ainda no início da segunda metade do século, o novo liberalismo, apesar de manter as premissas da liberdade individual, ainda advogava o planejamento estatal para capilarizar o desenvolvimento econômico [...], através da globalização no final dos anos 1980. (DUPAS, 2007 p.77).

Com a maior globalização dos mercados, uma nova forma de organização da produção, o modelo de consumo em massa, passa a ganhar força. Harvey, (1992), menciona 1914 como data inicial simbólica, quando Henry Ford, introduziu o dia de oito horas e cinco dólares como recompensa para os trabalhadores na linha automática de montagem. Com o domínio Taylorista/fordista, ${ }^{3}$ os estudos organizacionais e de desenvolvimento organizacional se afastaram dos aspectos territoriais e do desenvolvimento, baseando-se apenas no processo de acumulação e no consumo em massa. A administração científica em todas as facetas da atividade corporativa no local de trabalho, no marketing, na criação de produtos, nas estratégias de preços, na obsolescência planejada de equipamentos e de produtos, tornou-se o marco da racionalidade corporativa burocrática. (HARVEY 1992, p. 129; SCHUMPETER 1982). ${ }^{4}$

Desta forma entende-se que Schumpeter com sua obra "Teoria do Desenvolvimento Econômico", trouxe um novo paradigma em relação a escola clássica da economia, que menciona nos seus trabalhos a visão do desenvolvimento, não com uma visão meramente de crescimento. Segundo Schumpeter $(1982$, p. 9) os fatos nunca são puramente econômicos, dependendo também de outros fatores, como os sociais.

Na visão do autor o desenvolvimento econômico somente acontece quando as mudanças da vida econômica surgem por sua própria iniciativa, e não como um reflexo da alteração de fatores externos. 0 simples crescimento da economia através do aumento da riqueza e da população, portanto, não é considerado desenvolvimento. Schumpeter define claramente a diferença entre crescimento e desenvolvimento econômico, incluindo a possibilidade do desenvolvimento endógeno, com valorização das especificidades dos arranjos regionais, o que se aproxima da visão de Barquero (2001).

Schumpeter não considera o crescimento da economia derivado do crescimento populacional, ou de dados como renda e riqueza. $\mathrm{O}$ desenvolvimento, no sentido crítico, é um fenômeno distinto, que não pode ser observado no fluxo circular ou na tendência para o equilíbrio harmônico da epistemologia positivista. É uma mudança espontânea e descontínua, interativa nos canais do fluxo, perturbação do equilíbrio, que altera e desloca para sempre o estado de equilíbrio previamente existente. [...] Essas mudanças espontâneas e descontínuas no canal do fluxo circular e essas perturbações do centro do equilíbrio aparecem na esfera da vida industrial e comercial, não na esfera das

\footnotetext{
${ }^{3}$ Harvey (1992) é esclarecedor ao apresentar o modelo Taylorista em "Estudos de tempos e movimentos", aliado ao modelo de produção fordista, que pode ser entendido também como um modelo econômico, um estilo de vida baseado na acumulação de lucros, na customização em massa, e no consumo. Mais tarde, após os primeiros sinais de crise este modelo também se aliou ao keynesianismo. Tenório (2004, p.61) explica que o fordismo pode ser estudado como um modelo de organização da prịdueşão ou como sistema de acumulação de capital.

${ }^{4}$ Autores sobre desenvolvimento rural criticam a mera transposição destas técnicas de gestão para os produtores rurais que tem outras especificidades e particularidades.
} 
necessidades dos consumidores de produtos finais. (SCHUMPETER, 1985, p. 4748).

A visão de crescimento contrapõe a visão de desenvolvimento. 0 crescimento alinha-se a acumulação capitalista rígida com indicadores econômicos observados em primeiro lugar baseando as realidades sociais e organizacionais no mecanicismo do funcionamento de uma máquina da sociedade industrial. (HARVEY, 1992; MORGAN, 1996; RAMOS, 1996; SOBRAL e $\mathrm{PECl}, 2013)$.

A visão de desenvolvimento, como defendida embrionariamente por Schumpeter vai além do unidimensionalismo econômico como analisado por Marcuse (1973) na Obra a ideologia da sociedade industrial: o homem unidimensional. Nesta seara o desenvolvimento é analisado de forma multidimensional e multiescalar considerando a sociedade de múltiplas possibilidades, observando a tríade: econômico, social e ambiental, em contraponto a epistemologia positivista do crescimento com observância na tríade: burocracia, controle e eficiência.

Nota-se que a visão de crescimento e de desenvolvimento, também se aplica para a atividade rural. Muitos são os exemplos de políticas produtivistas visando mudar técnicas de produção rural e venda de produtos de multinacionais como insumos agrícolas, muitas vezes eliminando procedimentos familiares passados de geração em geração. O desenvolvimento rural, como outras áreas sofreu influências positivistas baseadas na acumulação do capital e nos métodos e teorias homogeneizadoras, não comprometidas com os aspectos multidimensionais e multiescalares.

Ramos (1989) alerta sobre a fragilidade das epistemologias nacionais e sobre a hegemonia do pensamento positivista normalmente atrelado a sociedade baseada no mercado e na acumulação de capital, recomendações que podem ser observadas também para o desenvolvimento rural.

\footnotetext{
Dessa forma, conclui-se que os agricultores familiares podem participar da produção no sistema do agronegócio (produzindo os mesmos produtos dominados pelo sistema [...], porém não estão inseridos nele, ou seja, eles participam de forma subordinada. Ao produzir no interior do sistema do agronegócio, o agricultor não tem o controle do processo; quem controla é o sistema do agronegócio. Essa condição de subordinação se caracteriza pela dependência em relação ao sistema, na escolha do que produzir, como produzir, para quem e quando comercializar a produção. Por fim, agricultura familiar e agronegócio são sistemas diferenciados; no entanto, são componentes de um mesmo território, pois ambos atuam no rural brasileiro. (KARNOPP e OLIVEIRA, 2012 p.225).
}

Para Navarro (2002), o termo desenvolvimento rural difere de outras terminologias usadas no meio rural como: desenvolvimento agrícola e desenvolvimento agrário, basicamente por uma característica específica, qual seja, aqui se trata de uma ação previamente articulada que induz (ou pretende induzir) mudanças em um determinado ambiente rural, envolvendo questões territoriais e sociais. 
Nesta perspectiva o desenvolvimento rural apresenta-se complexo, um fluxo de atividades ao longo do tempo que seguem constantemente mudando. A sua natureza, portanto, é de mudança, pois esta mudança é modelada, formada e remodelada na prática. Assim, para uma mesma pergunta podem aparecer respostas novas com o tempo. O desenvolvimento rural é construído passo a passo, de forma lenta e processual. Os processos de desenvolvimento rural vão, progressivamente, se desdobrando com o passar do tempo. Eles remodulam as práticas agrícolas, uma vez que estas mudanças serão parciais, desiguais e diferenciadas, contribuindo para que seja ampliada a heterogeneidade (VENTURA; PLOEG, 2010; DEPONTI, 2014 apud LOEBLER et al $(2017$, p. ).

O desenvolvimento rural é um processo complexo, interdisciplinar. O desenvolvimento de tecnologias de informação e de gestão, entretanto, são fatores importantes para o desenvolvimento das atividades dos agricultores familiares dentro de uma perspectiva de múltiplas possibilidades de desenvolvimento, não sendo objetivo de este ensaio fomentar a visão meramente economicista, apesar da importância dos controles econômicos e financeiros para qualquer atividade inclusive a atividade rural.

Batalha, Buainain, e Souza (2005) são enfáticos ao mencionar a necessidade de ampliarem-se esforços no sentido de utilização das ferramentas mais clássicas (marketing, logística, qualidade, custos, etc) na gestão agroindustrial adaptadas à realidade da agricultura familiar brasileira. $\mathrm{O}$ artigo dos autores aponta, nas suas conclusões, que um empreendimento rural, seja ele familiar ou não, deve ser gerido eficientemente como forma de garantir sua inserção no mercado e, por consequência, sua sustentabilidade. Aqui se verifica uma contradição, de um lado as técnicas de gestão econômica não garantem o desenvolvimento rural, mas a não utilização de ferramentas básicas de gestão econômica e financeira pode gerar miopia, dificultando uma gestão rural emancipadora.

Costabeber (2004) adverte sobre a falta de políticas de apoio para os produtores rurais, no sentido de assessoramento para tomada de decisões, sendo de um lado os interesses na venda de insumos químicos e, de outro lado uma embrionária discussão sobre sustentabilidade sem políticas concretas de implementação, bem como assessoria técnica e gestão.

Percebe-se claramente que para se caminhar para o desenvolvimento rural torna-se necessário também uma leitura histórica e das mudanças ocorridas na sociedade, além das relações de produção propriamente ditas, incluindo cada vez mais questões sociais, políticas culturais e ambientais. (RAMOS 1989).

Nesta esteira cabe destacar que a sociedade já se organizou de forma préindustrial, ou agrícola passando após a grande crise por um processo de industrialização. Na atualidade, discutem-se as mudanças em que a sociedade está passando em função da crise do processo de industrialização, discutindo-se questões multidimensionais, polimórficas, multiescalares evidenciando em termos de teoria e métodos também uma fragilidade da hegemônica escola positivista de explicar principalmente questões sociais como o desejado desenvolvimento rural. (RAMOS 1989; TOFFLER 1995; HARVEY 1992). 
Para Toffler (1995) as sociedades pré-industriais eram baseadas em uma agricultura que produzia seus alimentos, roupas e até moradias. Com a industrialização este cenário mudou surgindo um sistema dependente do capital e do consumo massificado. Estes argumentos deixam evidente a falta de políticas de desenvolvimento rural, bem como o movimento contrário, de um lado uma crise evidente no industrialismo e correntes defendendo crescimento rural nos moldes industriais principalmente após a década de 1970 como já citado por Navarro.

Da aproximação agricultura/indústria, formou-se um segmento produtivo que abrange os três setores da economia, o agronegócio, o qual adere à lógica da modernização e insere no campo, pressupostos industriais. Esse segmento tem grande representatividade econômica no mundo; porém, não pode ser tido como única forma de desenvolvimento rural que a teoria da modernização propõe, já que outros sistemas de produção são tão importantes quanto o agronegócio - agricultura familiar -, materializando, entretanto, outros resultados. ( KARNOPP e OLIVEIRA, 2012 p.226).

Toffler (1995) ainda faz uma análise histórica dos fluxos de capitais e da formação da riqueza, mencionando que a terra foi o primeiro fator de poder e de riqueza. Com a revolução das "chaminés", ou Revolução Industrial, o capital continuou sendo material através dos investimentos físicos das empresas. $\mathrm{Na}$ perspectiva pós-industrial evidenciam-se outras formas de fluxos de poder e de riqueza, baseados fortemente na informação.

Neste sentido, este ensaio irá abordar a importância das TICs e dos controles na propriedade rural para a melhoria da gestão, bem como propor controles econômicos e financeiros voltados para a atividade rural, visando ampliar a visão dos agricultores familiares com viés social e informacional no meio rural. ${ }^{5}$

\section{AS TICS E A GESTÃO RURAL}

As tecnologias de informação e comunicação, (TICs), estão cada vez mais presentes na vida dos brasileiros e no meio rural. Estas novas tecnologias poderiam ser utilizadas para melhoria do acesso à informação na atividade rural. Principalmente, no que se refere as tecnologias básicas de gestão econômica e financeira, visando uma melhor visão da atividade desenvolvida pelos agricultores familiares.

As tecnologias de informação ( $\mathrm{TI}$ ) também podem afetar de forma substancial a gestão dos negócios agroindustriais. Além de facilitar a busca, acesso, armazenamento e disseminação de informações, as modernas TI deverão cada vez mais servir como instrumento de comunicação e coordenação entre os agentes de um dado sistema agroindustrial. Neste último caso, tecnologias de troca informatizada de dados deverão assumir um aspecto vital nos anos vindouros. Sob

\footnotetext{
${ }^{5}$ Apesar da contradição entre desenvolvimento econômico e crescimento, a proposta desse ensaio é que os agricultores p(dêtexpertem da tendência à monocultura, da não utilização de técnicas de gestão que auxiliam na falta de visão holística, sendo um dos possíveis fatores que possibilitam a alienação no trabalho. Não se defende aqui a simples utilização de controles econômicos e financeiros e sim uma mudança de postura perante a sociedade.
} 
este aspecto, as TI são instrumentos importantes no aumento da eficiência e da eficácia das cadeias agroindustriais. Por outro lado, também podem levar a exclusão de pequenos produtores que não tenham acesso a esta tecnologia. (BATALHA, BUAINAIN, e SOUZA, 2005, p.9)

Os autores acima apresentam uma dialética relevante, pois na medida em que aumenta a utilização da TI nas atividades rurais, bem como a utilização de recursos de gestão podem também aumentar as desigualdades entre os produtores familiares inseridos nestas novas tecnologias e os que ainda não conseguiram acesso às TICs. O simples acesso as tecnologias de informação e a gestão na agricultura familiar, por certo não vai garantir desenvolvimento rural, mas principalmente na sociedade da informação é um fator relevante para uma visão integradora das atividades e pela emancipação dos agricultores.

As TI podem afetar de duas maneiras importantes a gestão dos agronegócios e, consequentemente, a agricultura familiar. A primeira delas relaciona-se a utilização das TI para gerenciamento de redes de pequenos agricultores familiares, sejam eles responsáveis ou não por empreendimentos agroindustriais. Nestes casos as TI viabilizam o planejamento e o controle da produção, ações de logística de distribuição e aprovisionamento, a análise e o controle de custos de produção e comercialização, a gestão dos canais de comercialização, etc. (BATALHA, BUAINAIN, e SOUZA, 2005, p.10).

Por outro lado, a utilização de tecnologias de informação por redes de supermercados para gestão da cadeia de produção, pode sem dúvida, como já mencionado ser um fator de exclusão de alguns agricultores familiares. A utilização da $\mathrm{Tl}$, por vários motivos, sejam eles organizacionais ou como ferramenta de acesso a informação, ou de integração na cadeia produtiva é um fator relevante para maior inclusão da produção primária na economia, principalmente através dos agricultores familiares.

Com o desenvolvimento da sociedade, a tendência evidente de novas formatações e arranjos regionais diversificados a tecnologia da informação pode ser entendida como um elemento fundamental de difusão do conhecimento e de inclusão dos agricultores familiares na sociedade da informação, diferente da sociedade baseada no mercado em que o capital fixo era o fator mais importante. (HARVEY 1992; TOFFLER 1995).

Este processo de inclusão digital supersimbólica, por ser entendido também como um processo de disseminação de conhecimentos e de inovação, é muito relevante para o desenvolvimento em todas as suas dimensões, assim como a inclusão no uso de metodologias de gestão econômica e financeira.

Assim, como a utilização da TI nas atividades rurais, o simples fato de implementar controles, não garante o desenvolvimento rural no sentido pleno, mas é uma importante ferramenta para análise econômica e financeira da atividade. 
derivam destas decisões, não é tratada de forma satisfatória na literatura nacional e internacional. Os trabalhos existentes nesta área estão quase sempre restritos aos aspectos financeiros e econômicos da gestão do empreendimento rural (custos, finanças e contabilidade). Tradicionalmente a questão da gestão na propriedade rural, especialmente aquela de menor porte, é abordada de forma muito compartimentada e específica (BATALHA, BUAINAIN, e SOUZA, 2005, p.12).

Apesar da crítica pelo demasiado enfoque da literatura apenas sobre os controles econômicos e financeiros, para uma gestão rural e compreensão da propriedade como um todo, é necessário o mínimo de conhecimento econômico e financeiro, mesmo sabendo que o simples fato de se utilizar relatórios gerenciais não garante uma melhor gestão, e muito menos uma visão de desenvolvimento rural. Para o efetivo desenvolvimento rural necessita-se ir além, envolvendo fatores econômicos e sociais, de crescimento e de desenvolvimento.

Como controle econômico, sugere-se uma leitura simplificada da conhecida no meio empresarial como DRE (Demonstração do Resultado do Exercício), sendo útil principalmente nas propriedades diversificadas para analisar a rentabilidade dos cultivares. A demonstração do resultado apresentada trabalha com informações referente à lucratividade das atividades rurais também denominada de análise econômica.

As Normas Brasileiras de Contabilidade Técnica- NBC-T 10.14 apresentam alinhada aos padrões internacionais de contabilidade define aspectos contábeis específicos de entidades diversas (atividades agropecuárias), também de acordo com Resolução 186 de 2009 do Conselho Federal de Contabilidade (CFC). Entretanto, ainda existe pouco material específico sobre a normatização de controles específicos para a atividade rural. Este estudo buscou embasamento nas normas brasileiras NBC 10.14 e na NBC 1000 que orienta a atividade de pequenas e médias empresas com algumas adaptações para a atividade rural.

Também as normas preveem as demais demonstrações contábeis, este estudo aborda a DRE e a Demonstração dos Fluxos de Caixa (DFC) como controles iniciais devido à dificuldade de levantamento de dados e de controles na atividade com isso não defendendo a ideia de que se devem fazer somente estes controles gerenciais, sendo os controles gerenciais de contabilidade de custos também aplicados à atividade rural.

A DRE traz a visão econômica dos negócios e pode ser desenvolvida por cultura, em se tratando de uma produção rural diversificada, para tal situação se faz necessário à utilização de recursos da contabilidade de custos que não são parte dos objetivos deste estudo. (FONTOURA, 2013). 
Figura 01 - Estrutura DRE da atividade rural

Culturas A

Receita bruta da atividade $\mathrm{R} \$$

(-) deduções da receita $\mathrm{R} \$$

= receita líquida da atividade

(-) Custo produtos vendidos $\mathrm{R} \$$

= resultado operacional $\mathrm{R} \$$

(-) despesas com vendas $\mathrm{R} \$$

(-) despesas administrativas $\mathrm{R} \$$

(-) outras despesas $\quad \mathrm{R} \$$

(+) (-) resultado econômico $\mathrm{R} \$$

= Resultado líquido do período R\$

Fonte: Adaptado da NBC TG 1000 (CFC, 2013).

Para o agricultor familiar ter conhecimento básico sobre as informações financeiras referente a sua atividade sugere-se a Demonstração dos Fluxos de Caixa (DFC) simplificada e adaptadas para a atividade rural. A demonstração sugerida é também simplificada para facilitar a coleta de dados, que de acordo com a literatura estudada, é um fator que impede que os agricultores familiares realizarem controles para melhorar a informação gerencial da propriedade rural. A DFC, sugerida parte das entradas e das saídas de caixa e deve ser estruturada, também, de acordo com as atividades, podendo ter quantas atividades forem necessárias dependendo da complexidade da atividade rural estudada.

As demonstrações sugeridas demonstram a viabilidade econômica e financeira das atividades rurais e para serem implementadas necessitam de controles internos nas propriedades que necessitam de maior aprofundamento metodológico que também não é o objeto deste ensaio. 
Figura 2 - Demonstração dos fluxos de caixa para atividade rural

\section{Atividades operacionais}

(+) Recebimentos de caixa pela venda de mercadorias e pela prestação de serviços;

(-) pagamentos de caixa a fornecedores de insumos e serviços;

(-) pagamentos de caixa a empregados e em conexão com a relação de trabalho;

(-) pagamentos ou restituição de tributos sobre o lucro, a menos que possam ser especificamente identificados com as atividades de financiamento ou de investimento;

(+) recebimentos e pagamentos de investimento, empréstimos e outros contratos mantidos com a finalidade de negociação, que são similares aos estoques adquiridos especificamente para revenda

\section{Atividades de investimento}

(-) pagamentos de caixa para aquisição de ativo imobilizado (incluindo os ativos imobilizados construídos internamente), ativos intangíveis e outros ativos de longo prazo;

(+) recebimentos de caixa resultantes da venda de ativo imobilizado, intangível e outros ativos de longo prazo;

(+) pagamentos para aquisição de instrumentos de dívida ou patrimoniais de outras entidades e participações societárias em empreendimentos controlados em conjunto (exceto desembolsos referentes a títulos considerados como equivalentes de caixa ou mantidos para negociação ou venda);

(+) recebimentos de caixa resultantes da venda de instrumentos de dívida ou patrimoniais de outras entidades e participações societárias em empreendimentos controlados em conjunto (exceto recebimentos referentes a títulos considerados como equivalentes de caixa ou mantidos para negociação ou venda);

(-) adiantamentos de caixa e empréstimos concedidos a terceiros;

(+) recebimentos de caixa por liquidação de adiantamentos e amortização de empréstimos concedidos a terceiros;

Atividades de financiamento

(+) caixa recebido por empréstimos

(-) pagamentos para amortização de empréstimo;

(-) pagamentos de caixa por um arrendatário para redução do passivo relativo a arrendamento mercantil (leasing) financeiro.

Fonte: Adaptado NBC TG 1000 ( CFC, 2013)

É importante verificar que estas demonstrações sugeridas sejam adaptadas a necessidade informacional dos agricultores familiares e simplificadas a fim de facilitar o uso básico destas informações, visto que a carência de metodologias adaptadas para atividade rural também impede a utilização deste tipo de metodologia.

Para utilização das informações econômicas e financeiras também é relevante mencionar que o planejamento do agricultor deve contemplar a separação das despesas e dos custos que são da atividade e as despesas da família, que muitas vezes também é um fator que impede a utilização dos controles na atividade rural.

A utilização das tecnologias de informação e controles da atividade rural é entendida como importante. Entretanto, cabe salientar que esta importância não se refere somente ao fato de se ter informações gerenciais econômicas e financeiras, mas sim contribuir para a formação de uma visão mais completa da atividade rural, no sentido de se ter uma visão mais emancipadora dos processos e que contribua com a tomada de decisão, que são normalmente vinculados a 
integração da produção e a monocultura e, que em muitos casos, não trazem o retorno para o trabalho do agricultor familiar.

\section{A IMPORTÂNCIA E A UTILIZAÇÃO DE CONTROLES NA PERCEPÇÃO DOS AGRICULTORES FAMILIARES}

Este ensaio busca analisar a importância da utilização das TICs bem como de controles gerenciais básicos por agricultores familiares. Assim como nas empresas de pequeno porte, historicamente a atividade rural não tem características de utilização destas tecnologias ou controles. Na organização préindustrial os agricultores focavam suas atividades na sustentabilidade das atividades produzindo para o sustento e para as necessidades básicas. ${ }^{6}$

Na medida em que a sociedade caminha para uma formatação baseada no conhecimento supersimbólico, e não mais somente no investimento em capital fixo a tecnologia da informação e a disseminação de conhecimentos e inovação tornam-se cada vez mais fatores relevantes. Entendendo o processo de organização e informatização dos agricultores familiares também como uma inovação em processos. ${ }^{7}$

Santos (1982) comenta que apesar do modo capitalista ser dominante as regiões são diferentes (formações sociais e espaciais), em função de questões históricas, econômicas e sociais, características das especificidades regionais. Neste sentido, a pesquisa social aplicada com agricultores familiares no que tange à tecnologia e ao uso de ferramentas gerenciais pode ser um fator potencializador para o desenvolvimento das regiões, em função das mudanças sociais em que a agricultura familiar também está exposta. "Diante de um turbilhão de críticas e mudanças tudo parecia em crise. As críticas ao positivismo se avolumavam e a busca de outros caminhos significou o desenvolvimento de outras correntes do pensamento geográfico". (LENCIONI, 1999, p.149).

Em função da profundidade do problema a busca empírica realizada com os agricultores familiares, buscou entender primeiro: Qual a importância da utilização de controles econômicos e financeiros? Quais controles já são utilizados na atualidade? Existe utilização de controles informatizados nas propriedades rurais? Para posteriormente propor controles básicos para melhoria da gestão da propriedade rural.

A base para a pesquisa empírica apoiou-se na percepção dos agricultores familiares em relação à utilização de controles, da tecnologia e da necessidade destas informações para melhoria gerencial. De acordo com Lencioni (1999) o estudo da percepção permite captar a essência das coisas com base em uma compreensão que nega o subjetivismo e o relativismo, afirmando o mundo vivido

\footnotetext{
${ }^{6}$ Autores ligados a Sociologia Econômica como Bell (1977) e Tofller (1995) mencionam as formas de organização da produção em pré-industrial ou agrícola, industrial, e pós-industrial. Na organização pós- industrial territorializada surgem novas formas e oportunidades para o meio rural desde que organizado e utilizando a gestão da informação com leitura holística das atividades.

${ }^{7}$ Sociedade pré-industrial: caracterizada pelas trocas de mercadorias, ausência papel-moeda, poder baseado na propriedade da terra (TOFFLER, 1995). Sociedade industrial ou do Chaminé, baseada na acumulação Fordista, no consumo massificado, na dependência do capital, e no crescimento econômico (TOFFLER, 1995; HARVEY 1992; TENÓRIO 2004). Sociedade póspingidusțial: alguns autores como: BELL (1977) e HARVEY (1992) discutem a possibilidade de uma sociedade pós-industrial, com flexibilização organizacional e do trabalho, e com novas formas de produção de riqueza vinculadas a tecnologia da informação e não mais nas formas rígidas de acumulação do capital.
} 
com possibilidade de viver a experiência sensível e simultaneamente poder pensá-la de forma racional.

Conforme já mencionado, a pesquisa de campo foi realizada com 10 famílias de agricultores familiares de Montenegro-RS, componentes da pesquisa intitulada "O uso e a apropriação das TICs pela agricultura familiar no Vale do Caí -RS. O levantamento dos dados foi realizado através de um questionário semiestruturado aplicado junto aos agricultores familiares nas respectivas propriedades, visando entender a percepção dos agricultores sobre a utilização e a importância das TICs para a gestão das propriedades.

De modo geral, pode-se dizer que todos os agricultores entrevistados no município de Montenegro têm consciência da importância da utilização das tecnologias de informação, de controles econômicos e financeiros, bem como operacionais nas propriedades. Entretanto, nenhum dos entrevistados realiza estes controles de forma informatizada e com periodicidade definida. Dos pesquisados apenas 4 agricultores se utilizam de algum controle manual na propriedade, normalmente entradas e saídas de insumos e produtos para comercialização.

O acesso à internet é possível por todos os entrevistados, somente um agricultor declarou não ter acesso ao sinal para utilizar a internet. Mas todos os agricultores declararam ser importante o uso para pesquisas e para questões comerciais que envolvem a propriedade.

Percebe-se, de modo geral, que os agricultores acreditam ser importante o uso de controle informatizado nas propriedades, mas não tem tempo, nem foco para realizar este trabalho de forma contínua e padronizada, inclusive em função das especificidades de cada propriedade.

Em relação às TICs, os agricultores familiares destacaram sua importância devido aos seguintes aspectos: a) levantar informações de produção e manuseio dos cultivares; b) acessar informações gerais sobre as tendências na atividade rural; c) pesquisas sobre climatologia e novos produtos; d) comercializar os produtos.

Em relação a utilização de controles os agricultores declararam também ser importante, principalmente nas propriedades com algum grau de diversificação para verificar o custo de produção, a rentabilidade e a formação do preço de venda dos produtos. Percebe-se que em relação aos entrevistados já existe alguma diversificação das propriedades, na maioria dos casos mais de três culturas. Entretanto, a bergamota apresenta-se como cultura principal em todas as propriedades demonstrando ainda forte influência monoprodutora na região.

Pode-se afirmar que há consciência da importância das TICs para melhoria da gestão das propriedades, embora ainda não há um costume na utilização de relatórios e controles gerenciais informatizados alinhados as especificidades de cada agricultor familiar. É importante salientar que os agricultores declararam a importância das tecnologias da informação e da utilização de controles na propriedade. Contudo, esta importância, em função das mudanças sociais citadas neste ensaio, tem tendência de, cada vez mais, ser necessária como um elemento fundamental para emancipação e autonomia dos agricultores. $O$ entendimento dos processos e das atividades desempenhadas passando por uma mudança cultural, no sentido de costume de registro poderia contribuir para qualificar a tomada de decisão e perfazer uma forma de inclusão na sociedade do 
conhecimento com características diferentes da sociedade baseada meramente no capital.

Essa visão pode ser entendida também como uma inovação vinculada aos arranjos regionais baseados no desenvolvimento de novas visões de mundo e de novas perspectivas multidimensionais e multiescalares, características da sociedade do conhecimento.

Ademais os agricultores alegam a falta de tempo para utilização de controles tão complexos, este fato aliado à baixa escolaridade, ensino fundamental incompleto, desfavorece o registro e o controle gerencial. Dentre as dificuldades observadas que dificultam o uso e a apropriação das TICs pelos agricultores familiares do Vale do Caí-RS, destacam-se: os agricultores apresentaram-se receosos e desconfiados; o registro das informações não é uma atividade do cotidiano deles e a maioria não possui o hábito de fazer registros; não compreendem como esta prática poderia ajudá-los no futuro para a gestão da propriedade e para a tomada de decisão; possuem medo/receio de se expor ou de que as informações sobre suas propriedades estivessem ao acesso dos demais participantes (BARCELOS et al, 2014).

\section{CONSIDERAÇÕES FINAIS}

O estudo apresentou uma reflexão inicial sobre a importância da utilização das TICs, bem como de controles econômicos e financeiros para uma gestão rural mais emancipadora, alinhada as novas tendências da sociedade do conhecimento e das transformações sociais evidenciadas principalmente após os anos 1970.

Utilizou-se o termo "emancipadora", e não "eficiente", de acordo com Freire (2005), como normalmente utilizado nas ciências sociais aplicadas, no sentido de que para este estudo não basta apenas realizar os controles nas propriedades, mas sim partindo da consciência e dos conhecimentos específicos dos produtores familiares desenvolverem uma visão mais completa, da propriedade como um todo e mais autônoma.

Bernstein (2011) destaca os efeitos do capitalismo industrial na agricultura, processo acelerado a partir da década de 1970 com o aumento da globalização e a equivocada simples proposição de produtores rurais vistos como empresas produtoras de mercadorias apesar da necessidade de melhoria nos processos de gestão.

Cabe resgatar novamente a contradição: não basta ter controles econômicos e financeiros para o desenvolvimento rural, se fosse assim estar-se-ia caindo no vício da visão do mero crescimento econômico. Entretanto, defende-se que os agricultores familiares tenham acesso as informações econômicas e financeiras específicas para cada propriedade para qualificar a gestão e a tomada de decisão frente às atividades desenvolvidas e com um viés de inclusão social.

Apesar deste levantamento qualitativo ser de profundidade e não visar generalizações, pode-se considerar que na maioria das propriedades existe consciência na utilização da TICs e de controles econômicos e financeiros, mas por alegação de falta de tempo a maioria dos agricultores familiares declaram não realizar estas técnicas nas propriedades. 
Em vez de fazer generalizações talvez seja interessante questionar ou sugerir novas agendas de pesquisa com base nos dados empíricos iniciais: Quais práticas auxiliariam o desenvolvimento rural da região? Quais as políticas públicas embricadas neste processo de desenvolvimento? As respostas a estes questionamentos seriam encontradas em um trabalho de levantamento econômico e financeiro junto aos agricultores familiares, ou o processo seria mais amplo? Que trabalho deveria ser realizado para, através da consciência da importância dos agricultores, se transformarem em práticas gerenciais e em desenvolvimento rural tão desejado?

Trabalhos atuais mencionam a importância do agronegócio e as dificuldades de realização de controles e de planejamentos econômico e financeiro e de custos nas propriedades, definindo o agronegócio como atividades ligadas a agricultura e a pecuária. (MARION, 2014; CALLADO E CALLADO, 2011; MORAES, BHER E FARIAS, 2016).

Este artigo amplia a discussão na visão interdisciplinar do desenvolvimento regional para a agricultura familiar que também tem representatividade e necessidade de análise econômica e financeira e de custos como uma dimensão relevante para o desenvolvimento emancipado das suas atividades assim como o agronegócio.

O desenvolvimento é um processo de mudança estrutural, situado histórica e territorialmente, caracterizado pela dinamização socioeconômica e consequente melhoria da qualidade de vida da população, sendo esta a diferença básica entre crescimento econômico e desenvolvimento, bem como na visão de desenvolvimento rural emancipador baseado na inovação e na leitura das mudanças sociais. (RAMOS 1989; SANTOS 1982). Para tanto, os caminhos a serem trilhados são complexos, pois exigem, por parte dos pesquisadores e dos policy makers a compreensão do simbólico e dos sentidos de vida dos agricultores familiares para que os instrumentos de controle gerencial não sejam mera reprodução e sim construções coletivas impregnadas de sentimento de pertencimento. 


\title{
Rural development: the importance of TICS and economic and financial controls in the vision of family farmers of the vale do Caí-
} RS

\begin{abstract}
The main objective of this essay is to understand the importance of Information and Communication Technologies (ICTs) and economic and financial controls in the view of the family farmers of the Vale do Caí-RS, as well as the social changes that occurred mainly after 1970 and its reflexes To the countryside. An empirical survey was carried out with the project "The use and appropriation of ICTs by family farms in the Caí-RS Valley" for 10 families of family farmers in order to understand the perception of these farmers on the theme. The study presents the discussion on rural development and the importance of ICTs. It also presents the methodological procedures, as well as initial suggestions for economic and financial controls applied to rural management. It was concluded that although one does not intend to generalize it can be stated preliminarily that the farmers have a typical influence of the monoproductive capitalist systems and lack of orientation on the use of the mentioned tools for improvement in the management of the rural property, understanding even though the economic dimension Is only one of several socio-environmental issues that are important for rural development.
\end{abstract}

KEY WORDS:ICTs, development, rural management. 


\section{REFERENCIAS}

BARQUERO, Vázquez. Desenvolvimento Endógeno em Tempos de Globalização. Porto Alegre: Fundação da Economia e Estatística, 2001. 280 páginas.

BATALHA, O Mário; BUAINAIN, Antônio Márcio; SOUZA, Meirelles Hildo. Tecnologia de Gestão e agricultura familiar.

BELL, Daniel. Las contradicciones culturales del capitalismo, Alianza, Madrid, 1977, $264 \mathrm{p}$.

BENKO, Georges. A ciência regional. Oeiras: Celta, 1999.

BERNISTEIN, Henry. A dinâmica de classe do desenvolvimento agrário na era da globalização. Sociologias, Porto Alegre, n 37, maio-agosto 2011 p. 52 a 81.

BOLTANSKI, Luck; CHIAPELLO, Ève. O novo espírito do capitalismo. WMF Martins Fontes, 2009.

CALLADO, Aldo Leonardo Cunha; CALLADO, Antônio André Cunha; ALMEIDA, Moisés Araújo. A utilização de indicadores de desempenho não-financeiros em organizações agroindustriais: um estudo exploratório. Organizações Rurais \& Agroindustriais, v. 10, n. 1, 2011.

COSTABEBER, José Antonio. Agroecologia: conceitos e princípios para a construção de estilos de agriculturas sustentáveis. Disponível em http://www.planetaorganico.com.br/trabCaporalCostabeber.htm

DALLABRIDA, Valdir. Roque. Desenvolvimento Regional: Por que algumas regiões de desenvolvem e outras não? Santa Cruz do Sul: Edunisc, 2010.

DUPAS, Gilberto. 0 mito do progresso.Novos estudos, março, 2007, p. 73 -89.

FREIRE, Paulo. Pedagogia do Oprimido. Rio de Janeiro, Paz e terra, 2005, 213p.

FONTOURA, BB Fernando. Gestão de custos. Uma Visão integradora e prática dos métodos de custeio. Editora Atlas, São Paulo, 2013, 225p.

KARNOPP, Erica; OLIVEIRA, Victor da Silva. Agronegócio e agricultura familiar: 
desenvolvimento Regional, Santa Cruz do Sul, V. 17, n 02, maio- agosto 2012, p. 215-228

LENCIONE, Sandra. Região e Geografia. A fenomenologia e o materialismo histórico nos estudos regionais. São Paulo:Edusp, 1999.

LOEBLER, L., KIST, R. B. B., DEPONTI, C. M., CADONÁ, M. O Curso Técnico a Distância em Agricultura e o Desenvolvimento Rural dos Municípios de Canguçu e de São Lourenço do Sul - Rio Grande do Sul. Revista Reflexão e Ação: UNISC. 2017.

MARCUSE, Herbert. A ideologia da sociedade industrial: o homem unidimensional. Tradução de Giasone Rebuá. Rio de Janeiro: ZHAR, 1973.

MARION, José Carlos. Contabilidade Rural: contabilidade agrícola, contabilidade da pecuária. São Paulo, Atlas 2014.

MARX, K. O capital: Crítica da Economia Política. Rio de Janeiro. Civilização Brasileira, 1974 5v.

MORAES, Gabriel Lemos de; Bher, Ariel; FARIAS, Everton Silveira da. Contabilidade de custos no agronegócio: um estudo bibliométrico dos artigos publicados no periódico custos e@ gronegócio on line. 2016.

HARVEY, David. A condição pós-moderna. São Paulo: Loyola, 1992.

DE PAULA, Ana Paula Paes. Para além dos paradigmas nos Estudos Organizacionais: o Círculo das Matrizes Epistêmicas/Beyond paradigms in Organization Studies: the Circle of Epistemic Matrices/Más allá de los paradigmas en Estudios Organizacionales: El Círculo de Matrices Epistémicas. Cadernos EBAPE. BR, v. 14, n. 1, p. 24, 2016.

RAMOS, A. Guerreiro. A nova ciência das organizações. Uma reconceituação da riqueza das nações. Rio de Janeiro: Editora da Fundação Getúlio Vargas, 1989.

SANTOS, Milton. Sociedade e espaço. A formação social como teoria e método. Petropolis:Vozes, 1982.

SHUMPETER, J. A teoria do desenvolvimento econômico.São Paulo: Abril Cultural, 1982. 
TENÓRIO, Guilherme, Fernando. Tecnologia da Informação transformando as organizações e o trabalho. Rio de Janeiro. Editora FGV, 2007. 216 p.

Guilherme, Fernando. Tem razão a administração? Ensaios de teoria organizacional. Editora Unijuí, $2^{\circ}$ Edição, 2004 136p.

TOFFLER, Alvin. "Powershift", as mudanças de poder: um perfil da sociedade do século XXI pela análise das transformações e natureza do poder. Rio de Janeiro, Record, 1995, p.613.

VENTURA, Flaminia; PLOEG, Jan Douwe Van Der. Rural development: some tentative conclusions. Rivista di Economia Agraria. Anno LXV, n.2, giugno 2010. A comparative analysis of rural development processes in China, Brazil and the European Union, 378 p. 319-336.

ZANDER, Navarro. Desenvolvimento rural no Brasil: os limites do passado e os caminhos do futuro.Revista Estudos Avançados, volume 16, número 44, 2002. São Paulo: USP, Instituto de Estudos Avançados.

Recebido: 28 jun. 2017.

Aprovado: 03 ago. 2017.

DOI: $10.3895 /$ rbpd.v7n1.5803

Como citar: FONTOURA, F. B. B.; DEPONTI, C. M. Desenvolvimento rural: a importância das TICS e dos controles econômicos e financeiros na visão dos agricultores familiares do Vale do Caí-RS. R. bras. Planej. Desenv.,Curitiba, v. 7, n. 1, p. 85-103, jan./abr. 2018. Disponível em: <https://periodicos.utfpr.edu.br/rbqv>.

Acesso em: XXX.

Correspondência:

Fernando Batista Bandeira da Fontoura

Av. Independência, 2293 - Universitário, Santa Cruz do Sul - RS

Direito autoral: Este artigo está licenciado sob os termos da Licença CreativeCommons-Atribuição 4.0

Internacional. 